\title{
COVID-19 VE DIABETES MELLITUS YÖNETIMI
} COVID-19 AND DIABETES MELLITUS MANAGEMENT

\author{
Hakan KORKMAZ ${ }^{1}$ \\ ${ }^{1}$ Süleyman Demirel Üniversitesi Tıp Fakültesi, İç Hastalıkları Anabilim Dalı, Endokrinoloji Bilim Dalı
}

Cite this article as: Korkmaz H. COVID-19 and Diabetes Mellitus Management. Med J SDU 2021; (ozelsayi-1):171-175.

Öz

Diyabetik hastalarda SARS-CoV-2 enfeksiyonu daha şiddetli seyretmekte, hastalığa bağlı yoğun bakım ihtiyaçları ve mortalite daha sık görülmektedir. Anjiyotensin dönüştürücü enzim-2 (ACE2), SARS-CoV2'nin ana reseptörüdür. Diyabetli hastaların akciğerlerinde ACE2 ifadesinin artması ve hiperglisemi ile bu reseptörlerin glikozillenmesi onları COVID-19'a daha duyarlı hale getirir. Bununla birlikte akut veya kronik hiperglisemi doğal ve edinsel bağışıklık fonksiyonunu bozarak diyabetli hastalarda COVID-19 enfeksiyonunun ağır geçirilmesine katkıda bulunur. SARS-CoV-2 yeni diyabet olguların gelişmesine neden olabileceği ve tip 1 diyabet sıklığında artışa yol açacağı da düşünülmektedir. Diyabetik hastalarda COVID-19 prognozunu iyileştirmede glisemik kontrolün sağlanması önemlidir. Glisemik regülasyonun sağlanması ile mortalitede önemli azalmalar sağlamaktadır. Solunum sıkıntısı olan ciddi hastalar ve kritik COVID-19 olgularında insülin tedavisi tercih edilmelidir. Hafif semptomatik veya asemptomatik bireylerde glisemik kontrol sağlanmışsa mevcut tedavisine devam edilir. $\mathrm{Bu}$ hastalarda oral antidiyabetik tedavilerin kesilmesine gerek yoktur. Glisemik kontrol sağlanamamışsa güncel diyabet tedavi kılavuzlarına göre tedavileri yoğunlaştırılır. COVID-19 tedavisinde kullanılan deksametazon ve remdesivir tedavilerinin glisemik kontrolü bozabileceği öngörülerek antidiyabetik tedavi revizyonu yapılmalıdır. Diyabetli COVID-19 olgularında kan şekeri hedeflerini $140-180 \mathrm{mg} / \mathrm{dl}$ arasında tutmalı, hipoglisemi riski olmayanlarda alt sınır 110 mg/dl'ye düşürülebilir.
Anahtar Kelimeler: Antidiyabetik ilaçlar, COVID-19, Diyabet

\section{Abstract}

SARS-CoV-2 infection has a more severe course in diabetic patients, intensive care needs and mortality related to the disease are more common in these patients. Angiotensin converting enzyme-2 (ACE2) is the main receptor of SARS-CoV-2. Increased ACE2 expression in the lungs of diabetic patients and glycolysis of these receptors with hyperglycemia make them more susceptible to COVID-19. In addition, acute or chronic hyperglycemia contributes to the severity of COVID-19 infection in patients with diabetes by impairing innate and acquired immune function. It is also thought that SARS-CoV-2 may cause the development of new diabetes cases and lead to an increase in the frequency of type 1 diabetes. Providing glycemic control is important in improving the prognosis of COVID-19 in diabetic patients. It provides significant reductions in mortality rates by providing glycemic regulation. Insulin therapy should be preferred in severe patients with respiratory distress and in critical COVID-19 cases. If glycemic control is achieved in mildly symptomatic or asymptomatic individuals, current treatment is continued. There is no need to discontinue oral antidiabetic therapies in these patients. If glycemic control cannot be achieved, their treatments are intensified according to the current diabetes treatment guidelines. Antidiabetic treatment revision should be made considering that dexamethasone and remdesivir treatments used in the treatment

İletişim kurulacak yazar/Corresponding author: drhorkmaz@yahoo.com.tr Müracaat tarihi/Application Date: 29.03.2021• Kabul tarihi/Accepted Date: 16.04.2021

ORCID IDs of the authors: H.K. 0000-0001-5066-6335 
of COVID-19 may impair glycemic control. Blood glucose targets should be between $140-180 \mathrm{mg} / \mathrm{dl}$ in diabetic COVID-19 cases, and the lower limit can be reduced to $110 \mathrm{mg} / \mathrm{dl}$ in those who do not have hypoglycemia risk.

Keywords: Antidiabetic drugs, COVID-19, Diabetes

\section{Giriş}

Diyabet, toplumlarda ağır bir yük oluşturan en büyük küresel halk sağlığı sorunlarından biridir. Son yıllarda gelişmiş ve gelişmekte olan ülkelerin çoğunda diyabet prevalansı artmıştır (1). Uluslararası Diyabet Federasyonu (IDF), 2019 verilerine göre dünya çapında 463 milyon yetişkinde diyabet olduğu tahmin edilmektedir (2).

Diabetes mellitus (DM), COVID-19 hastalarında en sık görülen komorbiditelerden biridir. Gözlemsel çalışmalar COVID-19'lu hastalarda diyabet prevelansının genel popülasyonda ki diyabet prevalansından çok farklı olmadığını gösterdi (3). Ancak diyabetik bireylerde özellikle de kontrolsüz hiperglisemisi olanlarda SARS-CoV-2 enfeksiyonunun daha ciddi seyrettiği ve yoğun bakım ünitelerine yatıș, mekanik ventilatör ihtiyacı ve ölüm gibi kötü sonuçların daha çok görüldüğü dikkat çekti $(4,5)$. Diyabetli COVID-19 hastalarının ölüm oranlarının diyabeti olmayanlara göre \% 50 daha fazla olduğunu görülmektedir (6). Glisemik regülasyonun sağlanması ile mortalite oranlarında önemli azalmalar sağlanmıştır (7).

Diyabetin SARS-CoV-2 enfeksiyonu üzerindeki rolüne iliş̧kin verilerin büyük çoğunluğunun patogenetik çıkarım yapmamıza imkan vermeyen gözlemsel çaIışmalar olduğu için diyabetli kişilerde COVID-19'un ciddi enfeksiyon ve ölüm riskini artırma nedeni tam olarak anlaşılmamakla birlikte bazı potansiyel mekanizmalar ileri sürülmektedir.

\section{Hipergliseminin COVID-19 Seyrini Değiştirmesinde Potansiyel Mekanizmalar}

\section{Epitel hücreleri ACE2 reseptör ifadesi ve ACE2 reseptör glikolizasyonunda ki artış} Şiddetli akut respiratuar distres sendromuna (ARDS) yol açtığı bilinen SARS-CoV-2'nin anjiotensin dönüşütürücü enzim 2 (ACE2) reseptörü aracılığıyla epitel hücre yüzeylerine bağlanarak enfekte ettiği artık iyi bilinmektedir. Diyabetli hastalarda hücre zarındaki ACE2 reseptör seviyesindeki artış virüsün hücrelere girişini kolaylaştırmaktadır. Ayrıca hiperglisemi ile bu reseptörün glikolizasyonun artması viral girişi daha da artırmaktadır $(8,9)$.

\section{Furin artışı}

Proprotein konvertaz subtilisin/keksin ailesine (PCSK) ait olan tip-1 membrana bağlı bir proteaz olan furin, koronavirüslerin hücreye girișinde rol oynar. Diyabet hastalarında furin artışının viral replikasyonu kolaylaştırdığı bildirilmektedir (10).

\section{3. İmmün yanıt bozukluğü ve hiperinflamatuar yanıtda artış}

DM, hem doğal gelen hem de edinsel bağışıklık sistemlerini değiştirerek enfeksiyona yatkınlığı artııı (11) . Diyabetli hastalar gecikmiş Th1 hücre aracılı bağışıklık ve geç abartılı bir Th17 cevabı ile karakterize bozulmuş bir edinsel bağışıklık yanıta sahiptir (12). Akut hiperglisemi durumunda proinflamatuar sitokinler olan interlökin-1 (IL-1), IL-6 ve tümör nekrotizan faktör- $\alpha$ (TNF- $\alpha$ ) sekresyonunda artışlar olmaktadır $(11,13)$. Sitokin fırtınası, yüksek seviyede sitokinlerin kontrolsüz salınması durumudur. Diyabetik kişilerde SARS-CoV-2 enfeksiyonu agresif inflamatuar tepkiye yol açmaktadır. Hiperglisemi inflamatuar makrofajları (M1) artırabilir. T hücrelerinin ve makrofajların düzensizliği sitokin ve kemokinlerin artışına neden olarak sitokin fırtınası tetkikler (14).

\section{COVID-19 ve Diyabet Gelişimi}

SARS-CoV-2 sadece diyabet kontrolünü bozmakla kalmayıp bazı yeni diyabet vakalarının gelişmesine yol açı̆̆ı düşünülmektedir. Bu durum SARS-CoV1'de gösterilmiştir (15). Bu bağlamda virüsün $\beta$ hücresinin insülin sekresyonunu bozduğu bildirilmektedir (16). Pankreas adacık hücrelerin ACE2 reseptörü eksprese ettiği ve SARS-CoV-1 virüsünün bu reseptörü aracılığıyla hücrelere girerek hücrelere zarar verdiği ve yeni diyabet olguların gelişimine yol açtığı gösterilmiştir $(17,18)$. COVID-19 hastalarında pankreas hasarının olduğuna dair yeterli bir kanıt olmadığından dolayı SARS-CoV-2 virüsünün $\beta$ hücrelerini enfekte ettiğini söylemek şu an için erkendir.

Coxsackie B, enterovirüs, kızamıkçık, sitomegalovirüs, Epstein-Barr virüsü ve su çiçeği gibi birçok virüs tip 1 diyabet gelişiminde rol oynamaktadır (19). Bununla birlikte koronavirüsle solunum yolu enfeksiyonlarının da tip 1 diyabet patogenezinde yer aldığı bilinmektedir. Bu nedenle önümüzdeki dönemde COVID-19 hastalığına bağlı tip 1 diyabet sıklığında artış olabileceği yönünde varsayımlar vardır $(20,21)$. 
Prediyabetik bireylerde COVID-19 enfeksiyonun kendisi veya hastalığının tedavisi için kullanılan ilaçların diyabet gelişimini tetikleyebileceği unutulmamalıdır. Glukokortikoitler oldukça etkili antiinflamatuar ilaçlardır. Buların suprafizyolojik dozlarda verilmesi glukoz intoleransı ve diyabet gelişimine neden olduğu iyi bilinmektedir (22). Bununla birlikte SARS-CoV-2 virüsü tedavisinde kullanılan lopinavir ve ritonavirin insülin direncini artırıp glisemik kontrolde bozulmaya yol açtığı da gösterilmiştir (23).

\section{COVID-19 ve Tip 2 DM Tedavi Yönetimi}

Diyabet yönetiminin temel taşlarından biri optimal yaşam tarzı değişikliklerine uyulmasıdır. Bu bağlamada tüm diyabetik bireylerin tıbbi beslenme ve egzersiz tedavilerini uygulamaları önemlidir. Bununla birlikte, pandemi süresince SARS-CoV-2 virüsünün bulaşını engellemek için yapılan sosyal izolasyonun COVID-19 hastalığını kontrol altına almada çok etkili olmasına rağmen bunun fiziksel aktiviteyi azalttığı ve paketlenmiş gıdaların tüketiminde artırışa yol açtı̆̆ı görülmüştür. Pandemi sürecinde diyabetik hastalara sağlıklı beslenme ve egzersizin öneminin vurgulanması daha da önem kazanmıştır (24).

Diyabetik bireylerde COVID-19 gelişmesi durumunda sıkı glisemik kontrolün sağlamak için kan şekeri düzeylerinin yakından takip edilmelidir. Hastaların klinik durumlarına göre antidiyabetik tedavi seçimi Tablo 1 'de özetlenmiştir. Hafif semptomatik veya asemptomatik bireylerde glisemik kontrol sağlanmışsa kullanmakta oldukları oral antidiyabetik ilaçlarda değişiklik yapmaya gerek yoktur. Glisemik kontrol sağlanamamışsa güncel diyabet tedavi kılavuzlarına göre medikal tedavi yoğunlaştırılması yapııı. Solunum sıkıntısı olan veya oral alımı çok kötü olan veya mekanik ventilasyon uygulanan diyabetik hastalarda kullanmakta oldukları oral antidiyabetik tedaviler kesilerek insülin tedavisine geçilir. İnsülin kullanan hastalarda klinik durumlarında göre insülin tedavi rejimi belirlenir. Oral alımı olmayan kritik hastalarda insülin infüzyon tedavisi tercih edilmelidir (25).

\section{İnsülin Dışındaki Antidiyabetiklerin COVID-19 Diyabetik Hastalarda Kullanımı}

Metformin: Karaciğerde AMP kinazı aktive etmektedir. AMP kinaz aktivasyonu ACE2 reseptöründe fosforilasyona yol açar (26). Bu tür değişiklikler SARS-CoV-2'nin bağlanmasını azaltabilir. Ayrıca metforminin antiproliferatif ve immünomodülatör etkilere sahip olduğu ve fare modellerinde pnömonide koruyucu rol oynadığı gösterilmiştir (27). Retrospektif bir çalışmada diyabetik COVID-19 hastalarında metformin kullanımının ARDS görülme riskini önemli ölçüde azalttığı gösterilmiştir. Bu nedenle diyabetli bir kişiye COVID-19 bulaştığında metformin kullanımı kontrendike olmadığı gibi faydalı bile olabileceği görüşü hakimdir (28).

Thiazolidinedion: Bu grupta kullanımda olan tek ilaç pioglitazondur. Karaciğer, yağ ve iskelet kas hücrelerinde insülin duyarlılığının artmasına neden olan nükleer reseptörleri (peroksizom proliferatör-aktive edici gamma-reseptör) aktifleștirerek etki gösterir (29). Glikoz düşürücü etkilerine ek olarak, thiazolidinedionların immünomodülatör etkileri de gösterilmiştir (30). Monosit ve makrofajlara etki ederek TNF- $\alpha$, IL-1 $\beta$ ve IL-6 sekresyonunu azaltmaktadırlar. Bu nedenle COVID-19 geçiren diyabetik bireylerde bu ilacın potansiyel bir faydası olabileceği düşünülmektedir (31).

Sulfonilüre: Bu ilaçların hipoglisemi riski mevcuttur. Özellikle oral alımı kötü kritik hastalarda bu ilacın devam edilmesi hipoglisemi riskini artırabilir. Hipoglisemi riski en düşük olan gliklazid'tir (32). Ek olarak COVID-19 kalp hasarına neden olabileceğinden pankreas reseptörüne seçici bağlanan gliklazid ve glimeprid gibi yeni kuşak sülfonilüreler daha güvenli olabilir (33).

\begin{tabular}{|l|l|}
\hline COVID-19 Klinik Durum & Öneri \\
\hline \multirow{2}{*}{ Asemptomatik veya Hafif semptomatik } & Kan şekeri regüle ise mevcut tedaviye devam \\
\cline { 2 - 2 } & $\begin{array}{l}\text { Kan şekeri regüle değilse güncel tedavi rehberine göre } \\
\text { tedaviyi yoğunlaştır }\end{array}$ \\
\hline Solunum sıkıntısı mevcut & $\begin{array}{l}\text { OAD kes, insülin başla (tercihen bazal bolus insülin } \\
\text { tedavi rejimi) }\end{array}$ \\
\hline Oral alımı bozuk veya Kritik Hasta & İnsülin infüzyon tedavisi başla \\
\hline
\end{tabular}

OAD, Oral antidiyabetik 
Sodyum glukoz ko-transporter-2 inhibitörü: Renal proksimal tübüllerde sodyum glukoz ko-transporter 2 (SGLT2) reseptörlerini bloke ederek glomerüllerinden filtre edilen glukozun yeniden absorbe edilmesini engellemekte ve idrarla glukoz atılımını artırmaktadırlar. Böylece insülinden bağımsız olarak kan şekerini düşürürler. SGLT2 inhibitörlerinin kardiyo ve renoprotektif etkilere sahip olduğu bilinmektedir $(34,35)$. Ayrıca laktat konsantrasyonlarını artıı intraselüler ph'ı azaltarak viral yükü azaltabileceği düşünülmektedir. $\mathrm{Bu}$ nedenle COVID-19 hastaları için faydalı olabilir (36). Bu ilaçları kullanırken dikkatli olunmalıdır. Öglisemik ketoasidozu gelişimini engellemek için yeterli hidrasyon ve yeterli insülinizasyon sağlanmasına dikkat edilmelidir (37).

DPP-4 inhibitörü: İnkretin hormonlar olan gastrik inhibitör polipeptid (GIP) ve glukagon benzeri peptid-1'i (GLP-1) parçalayan DPP4'ü inhibe ederek endojen inkretin hormon düzeyini artırmaktadırlar. Bu hormonlar, glikoza bağlı insülin salınımını uyararak önemli bir hipoglisemi riski oluşturmaksızın kan şekerini düşürür. Ayrıca yan etki potansiyeli düşük olup iyi tolere edilirler (38). Deneysel çalışmalar bu ilaçların inflamatuar yanıtı azalttığını göstermiştir (39). Ek olarak son veriler DPP4 inhibitörlerinin SARS-CoV-2 spike reseptörlerine biyoinformatik bir afinite gösterdiği, bu nedenle bu ilaçların virüsün reseptöre bağlanmasını engelleme potansiyellerin olduğu düşünülmektedir. Bu nedenle DDP4 inhibitörlerinin diyabeti olan COVID-19 olgularında faydalı olacağı düşünülmektedir $(40,41)$.

GLP-1 reseptör agonisti: GLP-1 reseptör agonistleri glukoz bağımlı insülin salınımını artııı glukagon salınımını inhibe ederek kan şekerini düşürürler. Hipoglisemi riskleri oldukça düşüktür. Ek olarak, gıda alımını ve vücut ağırlığını azaltmaya yardımcı olurlar. Bu nedenle aşırı kilolu diyabetik hastalarda oldukça faydalı olmaktadırlar (42). Ayrıca, kardiyo- ve renoprotektif yararlarının olması nedeniyle COVID-19'lu hastalar için faydalı olabilir $(43,44)$. Tip 2 diyabetik hastalarda TNF- $\alpha$, IL-1 ve IL-6 konsantrasyonlarında azalmaya neden olarak antiinflamatuar etkiye neden olurlar. Bu ilaçların iştah baskılayıcı özelliklerinden dolayı oral alımı bozuk COVID-19 hastalarında kullanımlarında dikkatli olunmalıdır (45).

\section{Kan Glukoz Hedefleri}

SARS-CoV-2 ile enfekte diyabetik hastalar için en iyi glisemik hedefleri belirlemek amacıyla sınırlı sayıda çalışma yapılmıştır. Çin'in Hubei kentinden yapılan retrospektif bir çalışmada hedef glukoz düzeyleri 180 $\mathrm{mg} / \mathrm{dl}$ altında tutmanın mortaliteyi azalttığı ve daha az ARDS, akut kalp ve böbrek hasarı, septik şok ve dissemine intravasküler koagülasyon (DiK) ile sonuçlandığı raporlandı (46). NICE-SUGAR çalışmasında kritik hastalarda hedef glukoz düzeyi $<180 \mathrm{mg} / \mathrm{dL}$ belirlenen hastalarda daha yoğun glisemik kontrol (81$108 \mathrm{mg} / \mathrm{dl}$ ) sağlanan hastalara göre daha iyi sonuçlar elde edilmiştir (47). Bu nedenle, yatarak tedavi gören hastalarda kan şekeri $>180 \mathrm{mg} / \mathrm{dl}$ ise insülin tedavisi başlanmalıdır. Genel olarak glisemik hedefin140-180 $\mathrm{mg} / \mathrm{dl}$ arasında alınması önerilir. Ancak hipoglisemi riski olmayan hastalarda glisemik hedef $110 \mathrm{mg} / \mathrm{dl}$ 'ye kadar düşürülebilir $(11,48)$. İntravenöz insülin infüzyonu alan hastalarda kan şekeri izlemi saatlik veya iki saatte bir yapılırken subkutan insülin alan hastalarda günlük 7 ölçüm şeklinde yapılır. Hasta kan şekeri ölçümlerini telefonla ileterek gerekli işlemler yapılabilir. Sağlık personelinin temasını azaltmak amacıyla kritik hasta dışındaki kendi ölçebilecek durumda olan kişilere bir glukoz ölçüm cihazı verilerek kendi kendine izleme öğretilebilir.

\section{Sonuç}

COVID-19 küresel salgını, özellikle diyabetli hastalar için önemli sağlık tehlikeleri oluşturmaktadır. Bununla birlikte pankreasın $\beta$ hücrelerinde ACE2'ye bağlanarak diyabetojenik bir etken görevi görebilir. Diyabetik hastalarda COVID-19 prognozunu iyileştirmede uygun antidiyabetik tedavinin planlanması ve glisemik kontrolün sağlanması önemlidir. Hiperglisemi, daha kötü sonuçlar ve mortalite artışı ile iliş̧ilendirilmiştir. ideal glisemik hedef $140-180 \mathrm{mg} / \mathrm{dl}$ arası kabul edilir. Hipoglisemi riski olmayanlarda alt sınır $110 \mathrm{mg} / \mathrm{dl}$ alınabilir.

\section{Kaynaklar}

1. Lin $X, X u Y$, Pan $X, X u J$, Ding $Y$, Sun $X$, et al. Global, regional, and national burden and trend of diabetes in 195 countries and territories: an analysis from 1990 to 2025. Sci Rep. 2020;10(1):14790.

2. IDF Diabetes Atlas. 9th edition. https://www.diabetesatlas.org/ en

3. Fadini GP, Morieri ML, Longato E, Avogaro A. Prevalence and impact of diabetes among people infected with SARS-CoV-2. J Endocrinol Invest. 2020;43(6):867-9.

4. Iacobellis G, Penaherrera CA, Bermudez LE, Bernal Mizrachi E. Admission hyperglycemia and radiological findings of SARSCoV2 in patients with and without diabetes. Diabetes Res Clin Pract. 2020;164:108185.

5. Zhang Y, Li H, Zhang J, Cao Y, Zhao X, Yu N, et al. The clinical characteristics and outcomes of patients with diabetes and secondary hyperglycaemia with coronavirus disease 2019: a single-centre, retrospective, observational study in Wuhan. Diabetes Obes Metab. 2020;22(8):1443-54.

6. Remuzzi A, Remuzzi G. COVID-19 and Italy: what next? Lancet. 2020;395:1225-8.

7. Zhu L, She ZG, Cheng X, Qin JJ, Zhang XJ, Cai J, et al. Association of blood glucose control and outcomes in patients with COVID-19 and pre-existing type 2 diabetes. Cell Metab. 2020;31(6):1068-77.e3. 
8. Brufsky A. Hyperglycemia, hydroxychloroquine, and the COVID-19 pandemic. J. Med. Virol. 2020;92(7):770-5.

9. Liu W, Hualan L. COVID-19: Attacks the 1-Beta Chain of Hemoglobin and Captures the Porphyrin to Inhibit Human Heme Metabolism. 2020. Doi:10.26434/chemrxiv.12120912.

10. Fernandez C, Rysa J, Almgren P, Nilsson J, Engstrom G, Orho-Melander $\mathrm{M}$, et al. Plasma levels of the proprotein convertase furin and incidence of diabetes and mortality. J Intern Med 2018;284(4):377-87

11. Jafar N, Edriss H, Nugent K. The Effect of Short-Term Hyperglycemia on the Innate Immune System. Am J Med Sci. 2016;351(2):201-11.

12. Hodgson K, Morris J, Bridson T, Govan B, Rush C, Ketheesan $\mathrm{N}$. Immunological mechanisms contributing to the double burden of diabetes and intracellular bacterial infections. Immunology. 2015;144(2):171-85.

13. Guo W, Li M, Dong Y, Zhou H, Zhang Z, Tian C. Diabetes is a risk factor for the progression and prognosis of COVID-19. Diabetes Metab Res Rev. 2020:e3319. doi: 10.1002/dmrr.3319.

14. Wang J, Meng W. COVID-19 and diabetes: the contributions of hyperglycemia. J Mol Cell Biol. 2021;12(12):958-62.

15. Rubino F, Amiel SA, Zimmet P. New-onset diabetes in COVID-19. N Engl J Med. 2020;383(8):789-90.

16. Chee YJ, Ng SJH, Yeoh E. Diabetic ketoacidosis precipitated by Covid-19 in a patient with newly diagnosed diabetes mellitus. Diabetes Res Clin Pract. 2020;164:108166

17. Hikmet F, Méar L, Edvinsson Å, Micke P, Uhlén M, Lindskog C. The protein expression profile of ACE2 in human tissues. Mol Syst Biol. 2020;16(7):e9610

18. Yang JK, Lin SS, Ji XJ, Guo LM. Binding of SARS coronavirus to its receptor damages islets and causes acute diabetes. Acta Diabetol. 2010;47(3):193-9.

19. Jaeckel E, Manns M, von Herrath M. Viruses and diabetes. Ann N Y Acad Sci. 2002;958:7-25.

20. Soliman AT, Al-Amri M, Alleethy K, Alaaraj N, Hamed N, De Sanctis V. Newly-onset type 1 diabetes mellitus precipitated by COVID-19 in an 8-month-old infant. Acta Biomed. 2020;91(3):ahead of print. doi: 10.23750/abm.v91i3.10074

21. Türkiye Endokrinoloji ve Metabolizma Derneği, Diabetes Mellitus ve Komplikasyonlarının Tanı, Tedavi ve İzlem Kılavuzu, 14 basım Diabetes Mellitus Çalışma ve Eğitim Grubu.2020.

22. Schacke H, Docke WD, Asadullah K. Mechanisms involved in the side effects of glucocorticoids. Pharmacol Ther. 2002;96(1):23-43

23. Noor MA, Parker RA, O'Mara E, Grasela DM, Currie A, Hodde SL, et al. The effects of HIV protease inhibitors atazanavir and lopinavir/ritonavir on insulin sensitivity in HIV-seronegative healthy adults. AIDS. 2004;18(16):2137-44.

24. Futatsugi $H$, Iwabu $M$, Okada-Iwabu $M$, Okamoto $K$, Amano Y, Morizaki Y, et al. Blood Glucose Control Strategy for Type 2 Diabetes Patients With COVID-19. Front Cardiovasc Med. 2020;7:593061. doi: 10.3389/fcvm.2020.593061

25. Muniangi-Muhitu $H$, Akalestou E, Salem V, Misra S, Oliver NS, Rutter GA. Covid-19 and Diabetes: A Complex Bidirectional Relationship. Front Endocrinol (Lausanne). 2020;11:582936.

26. Cuschieri S, Grech S. COVID-19 and diabetes: The why, the what and the how. J Diabetes Complications. 2020 Sep;34(9):107637

27. Kajiwara C, Kusaka Y, Kimura S, Yamaguchi T. Metformin mediates protection against Legionella pneumonia through activation of AMPK and mitochondrial reactive oxygen species. J Immunol. 2018;200(2):623-31.

28. Jiang N, Chen Z, Liu L, Yin X, Yang H, Tan X, et al. Association of metformin with mortality or ARDS in patients with COVID-19 and type 2 diabetes: A retrospective cohort study. Diabetes Res Clin Pract. 2020;173:108619.

29. Nanjan MJ, Mohammed M, Prashantha Kumar BR, Chandrasekar MJN. Thiazolidinediones as antidiabetic agents: A critical review. Bioorg Chem. 2018;77:548-67.
30. Ciavarella C, Motta I, Valente S, Pasquinelli G. Pharmacological (or Synthetic) and Nutritional Agonists of PPAR-y as Candidates for Cytokine Storm Modulation in COVID-19 Disease. Molecules. 2020;25(9):2076.

31. Chen Y, Niu Z, Cui J, Shen P. The inhibitory effect of troglitazone on macrophage differentiation mediated by repressing NF-kB activation independently of PPARy 2014;10(3):261-8.

32. Schopman JE, Simon AC, Hoefnagel SJ, Hoekstra JB, Scholten RJ, Holleman F. The incidence of mild and severe hypoglycaemia in patients with type 2 diabetes mellitus treated with sulfonylureas: a systematic review and meta-analysis. Diabetes Metab Res Rev. 2014;30(1):11-22.

33. Zeller M, Danchin N, Simon D, Vahanian A, Lorgis L, Cottin $Y$, et al. Impact of type of preadmission sulfonylureas on mortality and cardiovascular outcomes in diabetic patients with acute myocardial infarction. J Clin Endocrinol Metab. 2010;95(11):4993-5002.

34. Verma S, McMurray JJV. SGLT2 inhibitors and mechanisms of cardiovascular benefit: a state-of-the-art review. Diabetologia. 2018;61(10):2108-17.

35. Kelly MS, Lewis J, Huntsberry AM, Dea L, Portillo I. Efficacy and renal outcomes of SGLT2 inhibitors in patients with type 2 diabetes and chronic kidney disease. Postgrad Med. 2019;131(1):31-42

36. Cure E, Cumhur Cure M. Can dapagliflozin have a protective effect against COVID-19 infection? A hypothesis. Diabetes Metab Syndr. 2020;14(4):405-6

37. Filippas-Ntekouan S, Filippatos TD, Elisaf MS. SGLT2 inhibitors: are they safe? Postgrad Med. 2018;130(1):72-82

38. Doupis J, Veves A. DPP4 inhibitors: a new approach in diabetes treatment. Adv Ther. 2008;25(7):627-43

39. Higashijima Y, Tanaka T, Yamaguchi J, Tanaka S, Nangaku M. Anti-inflammatory role of DPP-4 inhibitors in a nondiabetic model of glomerular injury. Am J Physiol Renal Physiol. 2015;308(8):F878-87.

40. Solerte SB, Di Sabatino A, Galli M, Fiorina P. Dipeptidyl peptidase-4 (DPP4) inhibition in COVID-19. Acta Diabetol. 2020;57(7):779-83.

41. Li Y, Zhang Z, Yang L, Lian X, Xie Y, Li S, et al. The MERSCoV receptor DPP4 as a candidate binding target of the SARSCoV-2 spike. iScience. 2020;23(8):101400

42. Brunton SA, Wysham CH. GLP-1 receptor agonists in the treatment of type 2 diabetes: role and clinical experience to date. Postgrad Med. 2020;132(sup2):3-14.

43. Bethel MA, Patel RA, Merrill $P$, Lokhnygina $Y$, Buse JB, Mentz $\mathrm{RJ}$, et al. Cardiovascular outcomes with glucagon-like peptide-1 receptor agonists in patients with type 2 diabetes: a meta-analysis. Lancet Diabetes Endocrinol. 2018; 6(2):105-13.

44. Kristensen SL, Rørth R, Jhund PS, Docherty KF, Sattar N, Preiss D, et al. Cardiovascular, mortality, and kidney outcomes with GLP-1 receptor agonists in patients with type 2 diabetes: a systematic review and meta-analysis of cardiovascular outcome trials. Lancet Diabetes Endocrinol. 2019;7(10):776-85.

45. Santos A, Magro DO, Evangelista-Poderoso R, Saad MJA. Diabetes, obesity, and insulin resistance in COVID-19: molecular interrelationship and therapeutic implications. Diabetol Metab Syndr. 2021;13(1):23

46. Zhu L, She ZG, Cheng X, Qin JJ, Zhang XJ, Cai J, et al. Association of Blood Glucose Control and Outcomes in Patients with COVID-19 and Pre-existing Type 2 Diabetes. Cell Metab. 2020;31(6):1068-77.e3.

47. NICE-SUGAR Study Investigators, Finfer S, Chittock DR, Su SY, Blair D, Foster D, et al. Intensive versus conventional glucose control in critically ill patients. $\mathrm{N}$ Engl $\mathrm{J}$ Med. 2009;360(13):1283-97.

48. American Diabetes Association. 15. Diabetes Care in the Hospital: Standards of Medical Care in Diabetes-2020. Diabetes Care. 2020;43(Suppl 1):S193-S202. 